\title{
In Situ Hybridization of Hepatitis C Virus RNA in Liver Cells of an Experimentally Infected Rhesus Macaque
}

\author{
Selma Majerowicz ${ }^{+}$, Christopher G rief*, Debora Ferguson, Renata C Airano, \\ Marcia L Baptista, Marcelo A Pinto, O rtrud Monika Barth
}

\author{
Departamento de Virologia, Instituto Oswaldo Cruz- Fiocruz, Av. Brasil 4365, 21040-900 Rio de Janeiro, RJ, Brasil \\ *NIBSC, Potters Bar, Herts, UK
}

\begin{abstract}
The liver tissue of a rhesus macaque inoculated with hepatitis $C$ virus (HCV) has been analyzed for the presence of HCV RNA using the technique of in situ hybridization, both at light and electron microscopy levels. The animal was inoculated by the intrasplenic route using a HCV infected autogenic hepatocyte transplant. The serum sample used to infect the hepatocyte cells was characterized by polymerase chain reaction technique and shown to be positive for HCV RNA, genotype 3 with $10^{7}$ RNA copies/ml. In situ hybridization was performed using a complementary negative strand probe made with the specific primer. We were able to detect and localize viral RNA in altered membranes of the rough endoplasmic reticulum of infected liver cells, showing evidence of virus replication in vivo.
\end{abstract}

Key words: in situ hybridization - hepatitis C virus - rhesus macaque

Hepatitis $\mathrm{C}$ virus (HCV) is a major cause of chronic hepatitis, liver cirrhosis, and hepatocellular carcinoma (Houghton 1996). Identified in 1989, HCV has a positive stranded RNA and was classified as a Hepacivirus within the Flaviviridae family. Immunolabelling using electron microscopy methods of infected cell cultures revealed an association of HCV proteins and RNA with altered membranes of the endoplasmic reticulum, designated the membranous web, suggesting that this is the site of viral RNA synthesis and represents the replication complex of $\mathrm{HCV}$ (Egger et al. 2002, Gosert et al. 2003). The aim of the present study is to determine the intracellular localization of the viral RNA and to obtain a better understanding of $\mathrm{HCV}$ replication in vivo. In order to investigate the events in $\mathrm{HCV}$ infection, rhesus macaques were inoculated by the intrasplenic route using a HCV infected autogenic hepatocyte transplant in one animal, following the technique used by Rivas et al. (1994). The serum sample used was characterized by polymerase chain reaction technique as positive for HCV RNA, genotype 3 and shown to have $10^{7}$ RNA copies/ml. A suitable non-inoculated animal was also included in the experiment. Liver needle biopsies were obtained at two weekly intervals from rhesus monkey. For light microscopy observations, the tissue samples were fixed using neutral buffered $10 \%$ formalin and embedded in paraffin wax. For electron microscopy observations, tissue samples were fixed using $2 \%$ glutaraldehyde in 0.06 $\mathrm{M}$ sodium cacodylate buffer $\mathrm{pH} 7.4$ for $1 \mathrm{~h}$ at room tem-

Financial support: Fiocruz/Faperj, CNPq

${ }^{+}$Corresponding author. Fax: +55-21-2573.9591. E-mail:

selmam@ioc.fiocruz.br

Received 24 May 2004

Accepted 9 September 2004 perature followed by an overnight period at $4^{\circ} \mathrm{C}$. The samples were then processed for low temperature embedding using LR gold resin (Grief et al. 1991). Light and electron microscopy in situ hybridization was performed using a negative strand probe made with the K15 primer (Grief et al. 1997). In situ hybridization at the light microscopy level was performed on paraffin wax embedded necropsy liver tissue from animals sacrificed at 8 months into the experiment. Sections of paraffin wax embedded liver tissue were floated onto DEPC-treated water and picked up onto polylysine-coated glass slides. The sections were allowed to dry, dewaxed using xylene, and then rehydrated using solutions of ethanol followed by distilled water. The sections were then incubated with a 50 $\mathrm{mg} / \mathrm{ml}$ solution of proteinase $\mathrm{K}$ in PBS for $30 \mathrm{~min}$ at $37^{\circ} \mathrm{C}$ and washed using PBS followed by distilled water for 5 min. Endogenous alkaline phosphatase was blocked using a solution of $20 \%$ acetic acid, followed by a wash with distilled water. The sections were then fixed by incubating with industrial methylated spirits (IMS). The hybridization mixture was prepared by dilution of the digoxigeninlabelling HCV probe 1:10 using hybridization buffer, and boiling for 5 min prior to use. The hybridization mixture was added to each slide, which was then covered with a Sigma plastic coverslip and incubated overnight at $37^{\circ} \mathrm{C}$. The slides were washed with SET buffer and incubated with a 1:500 dilution of sheep anti-digoxigenin alkaline phosphatase using a Tris blocking buffer for $1 \mathrm{~h}$ at room temperature in a humidity chamber. Slides were washed with Tris-HCL buffer and the alkaline phosphatase detected by a colorimetric reaction. Following a further wash using Tris-HCL buffer the slides were stained, dried and mounted using Locktite superglue. Electron microscopy in situ hybridization was performed on infected and noninfected monkey liver tissue using a 1:10 dilution of the digoxigenin-labelled probes. Gold grids containing ultrathin sections of LR gold embedded liver tissue were 
immersed into droplets of the hybridization mixture and incubated for $4 \mathrm{~h}$ at $37^{\circ} \mathrm{C}$. The grids were washed by transferring onto droplets of TBS and then incubated with a 1/ 40 dilution of goat anti-digoxigenin antibody conjugated to $10 \mathrm{~nm}$ colloidal gold. The grids were then washed with distilled water and dried before contrast staining using a $2 \%$ aqueous solution of uranyl acetate. Despite the relatively low level of HCV infection, we were able to detect and localize viral RNA successfully in the liver biopsy material using in situ hybridization at light and ultrastructural levels. Positive RNA labelling was observed over liver hepatocytes at 57 days and 4 months post-infection. Light microscopy in situ hybridization showed a clear and moderate positive labelling of the hepatocytes in the animal challenged with HCV (Fig. 1). The negative control animal, which had not been challenged with $\mathrm{HCV}$, showed no in situ hybridization labelling. Electron microscopy observations showed that labelling was consistently found over the rER membranes and over vesicles which proliferate during HCV infection inside the rER cysterns (Fig. 2). The negative control material, which consisted of liver biopsies from animals transplanted with non-infected hepatocytes, did not show any specific labelling. In our experiment the in situ hybridization labelling, particularly at the ultrastructural level has enabled the clear localization of HCV RNA in the liver of infected rhesus macaque and provides useful data about in vivo intracellular $\mathrm{HCV}$ replication.

The ethic committee on research animal care at Fiocruz approved the study.

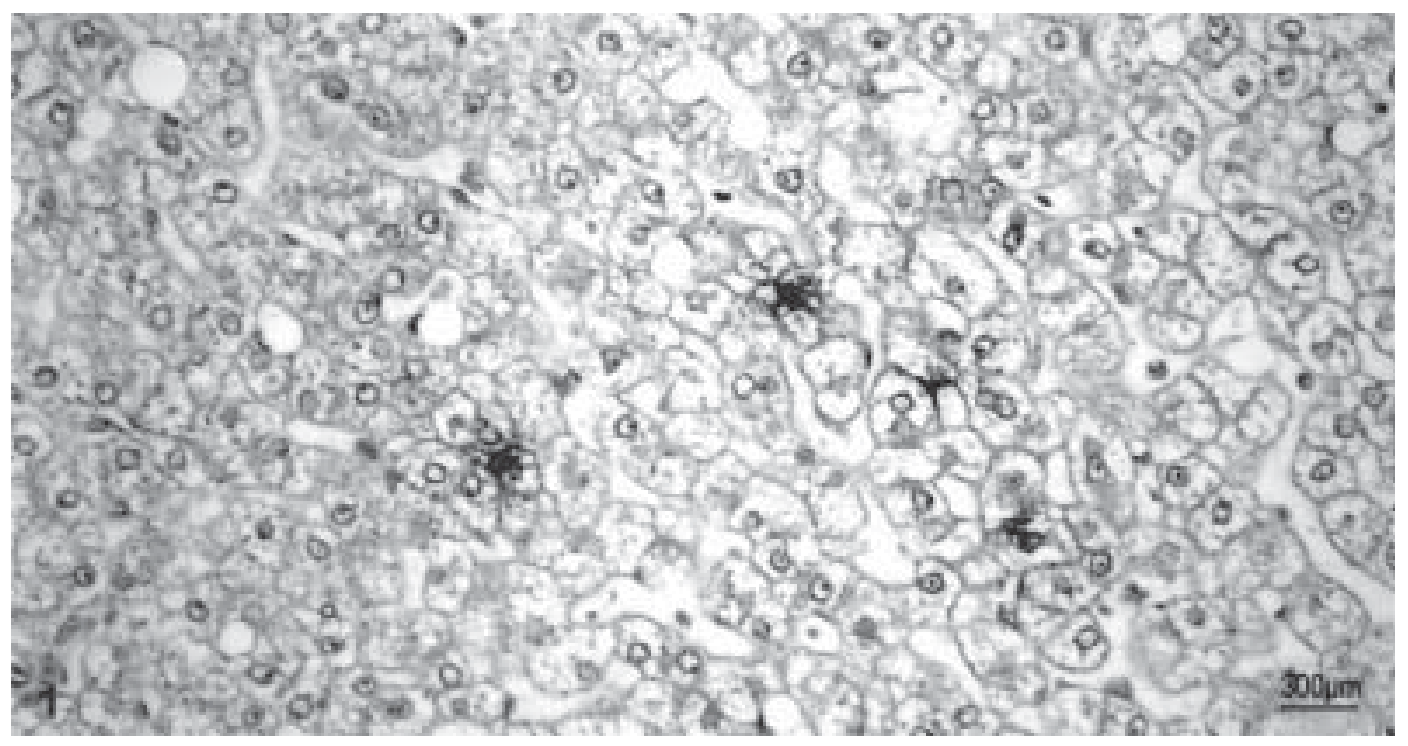

Fig. 1: light microscopy. Liver biopsy showing positive labelling of hepatocytes using in situ hybridization. 20x

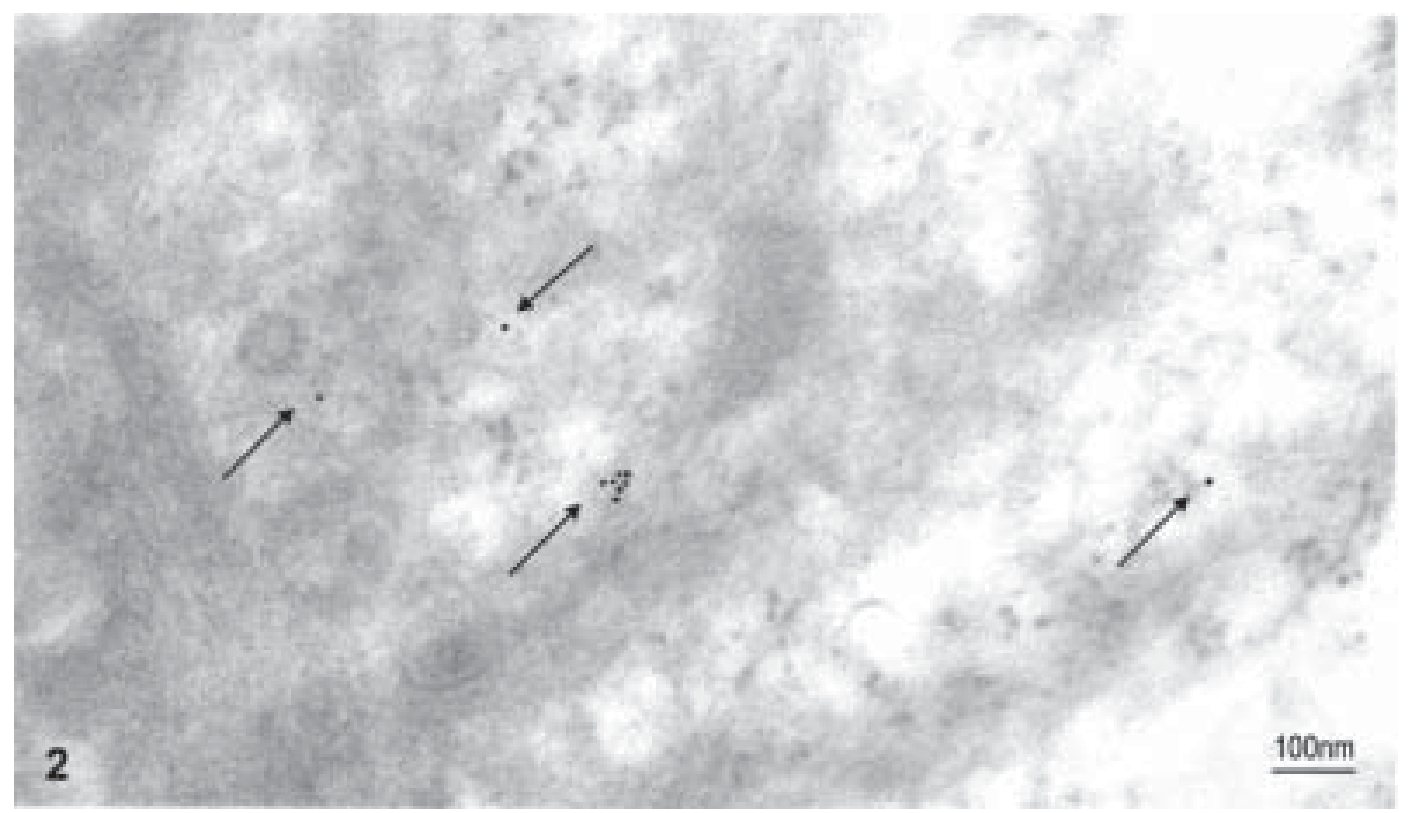

Fig. 2: electron microscopy. Hepatocyte showing colloidal gold particles over vesicles located inside the rER cysterns (arrows) using in situ hybridization labelling. 60,000x 


\section{ACKNOWLEDGEMENTS}

To Dr Renato Marchevsky, Dr Claudia Lamarca Vitral, Dr Renato Porrozzi, and Mr José Mariano da Silva, from Fundação Oswaldo Cruz, for the succeful realization of the experiment.

\section{REFERENCES}

Egger D, Wölk B, Gosert R, Bianchi L, Blum HE, Moradpour D, Bienz K 2002. Expression of hepatitis C virus proteins induces distinct membrane alterations including a candidate viral replication complex. J Virol 76: 5974-5984.

Gosert R, Egger D, Lohmann V, Bartenschlager R, Blum HE, Bienz K, Moradpour D 2003. Identification of the hepatitis $\mathrm{C}$ virus RNA replication complex in Huh-7 cells harboring subgenomic replicons. J Virol 77: 5487-5492.
Grief C, Farrar GH, Kent KA, Berger EG 1991. The assembly of HIV within the Golgi apparatus and Golgi derived vesicles of JM cell syncytia. AIDS 5: 1433-1439.

Grief C, Galler R, Côrtes LMC, Barth OM 1997. Intracellular localisation of dengue-2 RNA in mosquito cell culture using electron microscopic in situ hybridisation. Arch Virol 142: 2347-2357.

Houghton M 1996. Hepatitis C viruses. In NB Fields, DM Knipe, PM Howley (eds), Virology, 3rd ed., LippoincottRaven Publishers, Philadelphia, p. 1035-1058.

Rivas PA, Fabrega AG, Schwartz D, Dagiantis W, Ward MG, Blanchard J, Pollak R 1994. Transplantation of hepatocytes: an in-vitro and in-vivo study in canines. Cell Transplant 3: 193-201. 
